\title{
Comparison of Dolostone and Limestone Assessment Methods for Estonian Deposits
}

\author{
Julija Sommet ${ }^{1}$, Juri - Rivaldo Pastarus ${ }^{2},{ }^{1}$ Department of Mining TUT, Tallinn University of Technology; \\ Sustainability and Risk Assessment Center, OÜ OHUTU TK, ${ }^{2}$ Department of Mining TUT, Tallinn University of \\ Technology
}

\begin{abstract}
The goal of this study was to elaborate a methodology of sustainability assessment for developing advanced mining technologies. Last year sustainability assessment methods were conducted for Estonian deposits of dolostone and limestone. The elaborated sustainability assessment methods have shown that a three - level risk matrix monitoring scale gives a structured analysis results. The paper introduces with comparison of new Module Analysis (three - level risk matrix) and earlier used Module Analysis (simplest risk scale).
\end{abstract}

Keywords - Sustainability Assessment Method, Module Analyze, carbonate aggregates

\section{INTRODUCTION}

The mining industries worldwide are changing their mining practices by developing and implementing a variety of technologies and mining methods compatible with the principles of sustainable development. Adoption of the principles of sustainable development by the mining industry comes at a cost and requires major changes to current mining practices. Relating the different approaches to sustainable development across disciplines and against the background of the conceptual framework allows us to appraise their relative potentials and limitations. [1]

This paper deals with the introduction and comparison of sustainable assessment method for Estonian dolostone and limestone mining's. The sustainable method was developed for Estonian deposits last year for a mining company OÜ Väo Paas. In this case, a module analyze is in use to measure and compare different parameters. For the limestone parameters gradation a three-level risk matrix scale was used from the British Standard BS 8800 „Occupational health and safety management systems" ${ }^{\text {"1 }}$ and for the dolostone a simple scale (simply using periodic numbers) was used, where a zero point " 0 " was included and five " 5 " point was the maximum measurement. Two different parameter scales have been used to compare limestone and dolostone to find out which one is more convenient.

\footnotetext{
${ }^{1}$ Written with the help of industry, safety practitioners and the Health and Safety Executive (HSE), this British Standard will help organizations develop a framework for managing $\mathrm{OH} \& \mathrm{~S}$ so employees and others, whose health and safety might be affected by the organization's activities, are adequately protected. The guidelines in BS 8800:2004 are based on general principles of good management and are designed to enable the integration of OH\&S management within an overall management system. [7]
}

The aim of the work was to evaluate the practical output of mining companies' competitiveness in Estonia on the basis of the consumer's wishes and needs, because sustainability depends at least on the environment, socio-cultural parameters and also on the technological level. This paper will also give a more convenient method for the gradation and sustainable assessment analysis of non-metallic aggregates developed on Estonian deposits.

Reference [2] shows that, since sustainable development became the catchword in international discussions, several approaches to sustainability assessment have been developed. In order to measure or predict the sustainability of a land use system or a society, one must consider the inherent problems of analysis and its complex systems. Appropriate scales and time horizons must be chosen; the preconditions and requirements for operationalization and quantification of sustainability must be defined; and the philosophy and value system behind this concept and its translation into policies must be made explicit. On the other hand, the ethical and political convictions behind the multitude of policy recommendations made under the umbrella of sustainable development often remain obscure. There is a need to develop criteria that can be used to indicate to what degree strategies and policies contribute to sustainable development.

\section{THE METHODOLOGY OF ANALYSIS}

To organize an optimal analysis for both deposits it was proposed to use a module analyze table with a matrix of influence risks values, where the final product was considered as a process and divided to four main parts: economic, environmental, technical feasibility and social - cultural.

Economic viability demonstrates if the company's well being is at a maximum; is it possible to ensure efficient use of all resources, natural and otherwise, by maximizing or minimizing economical rents; help to seek or identify and internalize environmental and social costs; maintain and enhance the conditions for viable enterprise, ensure a fair distribution of the costs and benefits of development. [1]

The environmental quality part contributes in preventing undesired collapses and hazards related to them, emissions to atmosphere and aquifer. Conditions for sustainable mining in densely populated regions allows transforming large areas of mined areas to suitable farmland or building areas. Minewater could be used for drinking water after self-cleaning. Mine closure is the period of time when the extracting activities of a mine have ceased, and final decommissioning 
and mine reclamation are being completed. It is generally associated with reduced employment levels, which can have a significant negative impact on local economies. It is also the period when the majority of mine reclamation is completed, making the land safe and useful again. [1]

Technical feasibility and the technological scheme depend on extraction methods. For this reason, there is a great variety of possible combinations of processes in the excavation field. For carbonate rock materials, the analysis table is given below (at Table II and Table III). [4]

Socio-cultural well-being includes respect and a reinforcement of the fundamental rights of human beings, including civil and political liberties, cultural autonomy, social and economic freedoms, and personal security. Any company should seek to sustain improvements over time; ensure that the depletion of natural resources will not deprive future generations through the replacement with other forms of capital. [1]

A specific large-scale monitoring tool and indicators were developed in order to access each branch of mining, because on a small-scale this is not very effective and illustrative; it does not include the technical indicators part, which is important.

For the analysis of dolostone mining aspects, were used a 5point scale including the zero point value (" 0 " - very minimal or no impact, "1" - minimal impact, "2" - medium impact, " 3 " - considerable impact, "4" - very important impact and " 5 " - no positive outcome activity, impact is gross). [3]

A different scale was used for limestone mining: three-level risk matrix scale (descriptions are shown at the Table I), where minimal risk level is " 1 " point and point " 5 " means that risk is very high. Risk evaluation on Table I is based on the British Standard BS 8800 „Occupational health and safety management systems" and it means that a non-existent risk (I) is minimal risk and can be ignored, but it is necessary to ensure that this remains stable in the future; very low risk is insufficient risk (II) - not necessarily to apply measures, aim is to find a better solution that does not create additional expenses; acceptable risk (III) - necessary measures should be taken to reduce risks, such as staff informing about risks, situation analyze and applying additional supporting measurements; acceptable risk with monitoring (IV) immediately steps should be taken to reduce the risk, increasing staff awareness of risk level, training on measures to reduce this risk; unwarranted risk - very high risk, shows that measures to eliminate this risk must be implemented swiftly to remedy the situation. [7] For example, the environmental parameters module in Table II shows unwarranted risk for volume of unused material/risk of exhaustion, because it was left only $325 \mathrm{~m}^{3}$ to excavate of a total amount of $3049 \mathrm{~m}^{3}$. Validity of extraction permission risk is also unwarranted considering that it was left only one month for permission and new permission was not available yet.

Both analyses are based on general characteristics of carbonate rock mining. The new methodology has an analogy with the Safety Risk Assessment Method by its evaluation system. Nevertheless both analyses are easy to compare and as the fact have an analogy with the workplace safety risks estimation, life cycle assessment (LCA) or the nowadayspopularized environmental EMAS Easy ${ }^{2}$ system by its sets of measured components. It is recommended to make analyze at least once every three months. If company is larger than micro company $(<10)$ in accordance to the number of employees by EU Commission Regulation No 70/2001, than it is advised to divide the analysis of the business by several branches. These module analyze tables (Table I and Table II) were composed in the Excel program. For more information see an overview of dolostone analyze Table II below and Table III of limestone analyze.

Analyze should provide a qualified image for the end user and company owners. One of two modules analyze table systems should work better than the other and provide more accurate data. For both analyzes all economical indicators data was real and taken from the accounting records program; summarized income statements and evaluations percentage shown for 1 worker of the total income of Väo Paas OÜ mining company Kareda dolostone deposit and Tondi - Väo limestone mining branch over October, 2011. The economical indicators contain a part of the balance of the mining remnant stock and analyze data of unused material, its volume which shows a risk of mining exhaustion, and a numerical overview of trading income and operating expenses. In assessing the summarized incoming risk, the V. Pareto principle 80/20 was taken as a basis.

TABLE I

RISKS DESCRIPTIONS

\begin{tabular}{|c|c|c|c|}
\hline \multicolumn{4}{|c|}{ The Effects of Consequences } \\
\hline INJURY & INSUFFICIENT & $\begin{array}{c}\text { DANGEROUS OR } \\
\text { HARMFUL }\end{array}$ & VERY INSECURE \\
\hline UNLIKELY & $\begin{array}{c}\text { NON-EXISTENT } \\
\text { RISK (I) }\end{array}$ & $\begin{array}{c}\text { INSUFFICIENT } \\
\text { RISK (II) }\end{array}$ & $\begin{array}{c}\text { ACCEPTABLE } \\
\text { RISK (III) }\end{array}$ \\
\hline LIKELY & $\begin{array}{c}\text { INSUFFICIENT } \\
\text { RISK (II) }\end{array}$ & $\begin{array}{c}\text { ACCEPTABLE } \\
\text { RISK (III) }\end{array}$ & $\begin{array}{c}\text { ACCEPTABLE } \\
\text { RISK WITH } \\
\text { MONITORING } \\
\text { (IV) }\end{array}$ \\
\hline VERY & $\begin{array}{c}\text { ACCEPTABLE } \\
\text { RISK (III) }\end{array}$ & $\begin{array}{c}\text { ACCEPTABLE } \\
\text { RISK WITH } \\
\text { MONITORING } \\
\text { (IV) }\end{array}$ & $\begin{array}{c}\text { UNWARRANTED } \\
\text { RISK (V) }\end{array}$ \\
\hline
\end{tabular}

The $80 / 20$ Rule means that in anything a few (20 percent) are vital and many ( 80 percent) are trivial. The Pareto's "principle, the 80/20 Rule, should serve as a daily reminder to focus 80 percent of your time and energy on 20 percent of your work that is really important". [8]

\footnotetext{
${ }^{2}$ Interest in the environmental performance of organisations is continually increasing. Operating without taking into account the environmental consequences of their actions becomes almost impossible for organisations. Organisations with a proactive approach to environmental challenges look for ways to continually improve their environmental performance. EMAS is the premium environmental management tool to achieve this. It leads to enhanced performance, credibility and transparency of registered organisations. Currently, more than 4,500 organisations and approximately 7,800 sites are EMAS registered. [6]
} 
For example Table II below, shows summarized trading income for whole company or for certain deposit, different operating expenses and activity profit or loss. All data should be real and it is easy to follow by accounting records program. Total values are shown in Euro. The deposit-branch economical parameters depend on total economic aspects of the company. If employees' percentage in branch is $15 \%$, it means that other parameters in the overview table should not be less than 15 , in other case the risk is critical for the filial and production should be suspended. [3]

\section{TABLE II}

OVERVIEW OF INDICATORS USED IN THE DOLOSTONE MODULE ANALYZE

\begin{tabular}{|c|c|c|}
\hline Economical Indicators & $\begin{array}{l}\text { Risk } \\
\text { Level }\end{array}$ & $\begin{array}{l}\text { Kareda Branch, } \\
\%\end{array}$ \\
\hline Summarized Trading Income & 2 & 19,7 \\
\hline \multicolumn{3}{|l|}{ Operating Expenses } \\
\hline * Goods, Commodities, Aggregate, Service & 2 & 20,9 \\
\hline \multicolumn{3}{|l|}{$*$ Office Miscellaneous Operating } \\
\hline Expenses & 1 & 17,9 \\
\hline * Labor costs & 1 & 9,7 \\
\hline Employees & 0 & 15,4 \\
\hline Depreciation & 4 & 29,2 \\
\hline Economical Activity Profit/Loss & 3 & 23,2 \\
\hline Presence of competitors within $50 \mathrm{~km}$ & 4 & \\
\hline Total risk is less than the average & 2 & \\
\hline \multicolumn{3}{|l|}{ Environmental indicators } \\
\hline Petroleum content in the water & 0 & \\
\hline Suspended soils in water & 0 & \\
\hline Dust contamination in the air & 0 & \\
\hline Noise level & 0 & \\
\hline Vibration level & 0 & \\
\hline Water pumping influence & 0 & \\
\hline Energy cost & 1 & \\
\hline Average petroleum use & 5 & \\
\hline Volume of unused material/risk of exhaustion & 0 & \\
\hline Soil contamination & 1 & \\
\hline Max annual rate, thousands $\mathrm{m}^{3}$ & 3 & \\
\hline Mining allotment area, ha & 2 & \\
\hline Mining clime area, ha & 2 & \\
\hline Residues /wastes & 1 & \\
\hline Chemicals in use & 2 & \\
\hline Mining closure project & 5 & \\
\hline Validity of extraction permission & 0 & \\
\hline Existence of new extraction permission & 5 & \\
\hline Total risk is less than the average* & 2 & \\
\hline \multicolumn{3}{|l|}{ Technical indicators } \\
\hline Average Technical Durability & 5 & \\
\hline Endure seasonal effects & 5 & \\
\hline Flexibility/adaptability of techniques & 3 & \\
\hline Frequently maintenance & 4 & \\
\hline Reliability/security & 1 & \\
\hline $\begin{array}{l}\text { Total risk is more than the average, } \\
\text { supporting measures should be taken** }\end{array}$ & 4 & \\
\hline \multicolumn{3}{|l|}{ Social-cultural indicators } \\
\hline Awareness/participation in tenders & 0 & \\
\hline Competence/information requirements & 0 & \\
\hline Web activity & 0 & \\
\hline Quality requirements & 0 & \\
\hline Work Safety Manuals & 0 & \\
\hline Labor accidents & 1 & \\
\hline Work Safety Risk Assessment & 0 & \\
\hline Reclamations & 0 & \\
\hline Total risk is minimal & 0 & \\
\hline
\end{tabular}

In order to develop the sustainable analyze, the environmental annual reports of both branches were used to describe the environmental indicators part. Validity of extraction permission should be compatible with overview data time. Some new environmental indicators were added to limestone analyze, such as the existence of an Environmental Management Handbook, where the environmental aspects, goals, missions, actions and needs to protect and improve environmental conditions in and around the facilities are clearly demonstrated. In case if the Handbook does not exist, the risk is very high (" 5 " points), when the Handbook is completed and approved by the company board member, then the risk is minimal (" 1 " point); in other cases the risk level varies according to the stage of the draft handbook. For this limestone deposit analyze risk point value was measured like point " 3 ", because ecological mapping was done, responsible personnel was trained, but Handbook confirmation of the finalization remained not completed. At this time in Estonia, the existence of a handbook in not strictly required, but rather recommended by the standards. Point " 3 " means that risk is acceptable, but some additional activities are recommended to improve the average sustainability of the mining company.

All parameters at the modules of Tables II and III are considered and associated to each indicator by the local Estonian normative or legislations regulations and law, most of them are based on European Union standards (at least 39 normative: Mining Law, Water Statute, Waste Statute, Waste Oil Management Requirements, Municipal Waste Sorting Procedures, Fire Safety Requirements, Occupational Health and Safety Acts, etc).

In the limestone sustainability assessment, the sociocultural indicators pertaining to awareness and participating in tenders were divided into two separate parts. These two components are important, because they provide an effective promotion for the company and help the company to become widely known among local residents. The next new significant indicator is the labor middle age, which was calculated by the average value for all company employees (the overall number of employees at the time analyze was made was 41 persons); the nearest approximate quantity was 50. According to Estonian requirements, the Work Safety Risk Assessment should be archived 55 years since its first measurement, mostly because of the workers average life expectancy. Being that the middle labor age of workers were 50, risk was estimated like acceptable upon condition of an annual health check monitoring at the expense of the corporation.

Another indicator, like participation in tenders shows how felicitously company can sell their goods and how successfully they use an opportunity offered by the state or other local companies. In that case risk point " 5 " could mean absolute inaction.

The expected result of this study was to explore a better type of analyzing methodology for sustainable assessment in mining management. In case the total risk of an analyze is valid or more than the average (if point " 5 " was estimated as maximum, then " 2,5 " point will be average), then supporting measures should be taken in these area of the company's activity. The sustainable assessment develop the scientific output of the optimal activity analyze, to ensure the practical 
output of the company's competitiveness in Estonia on the basis of the consumer's wishes and needs and to provide an optimal assessment of the capacities of different groups based on the company needs. The urgency of the research consists in management efficiency in the current market conditions. It is necessary requirement of the activity improvement and company development for competitive advantages. For more accurate data research should be continued. [3]

TABLE III

OVERVIEW OF INDICATORS USED IN THE LIMESTONE MODULE ANALYZE

\begin{tabular}{|c|c|c|c|}
\hline Economical indicators & $\begin{array}{l}\text { Risk } \\
\text { level }\end{array}$ & \begin{tabular}{|l|} 
Filial \\
branch \\
$\%$
\end{tabular} & $\begin{array}{l}\text { For } 1 \\
\text { person } \%\end{array}$ \\
\hline Summarized Trading Income & 1 & 53,0 & 100 \\
\hline \multicolumn{4}{|l|}{ Operating Expenses } \\
\hline $\begin{array}{l}\text { * Goods, Commodities, Aggregate, } \\
\text { Service }\end{array}$ & 3 & 42,6 & 33 \\
\hline * Office miscellaneous operating expenses & 1 & 30,2 & \\
\hline * Labor costs & 2 & 35,7 & 16 \\
\hline Labor persons & - & & \\
\hline Depreciation & 4 & 58,7 & 15 \\
\hline Economical Activity Profit/Loss & 2 & 83,0 & 28 \\
\hline $\begin{array}{l}\text { The presence risk of competitors within } 50 \\
\mathrm{~km}\end{array}$ & 3 & & \\
\hline Total risk is low & 2 & & \\
\hline
\end{tabular}

Environmental indicators

Petroleum content in the water

Suspended soils in water

Dust contamination in the air

\begin{tabular}{l} 
Noise level \\
\hline
\end{tabular}

Vibration level

Water pumping to the aquifer

Energy cost for this branch

Average petroleum use

Volume of unused material/risk of

exhaustion

Soil contamination

Max annual rate, thousands m3

Mining allotment area, ha

Mining clime area, ha

Residues /wastes

Chemicals in use

Mining closure project

Validity of extraction permission

Existence of new extraction permission

Existence of Environmental management

Handbook

\begin{tabular}{|c|c|}
\hline \multicolumn{2}{|l|}{ Total risk is valid } \\
\hline Technical indicators & \\
\hline Average Technical Durability & 5 \\
\hline Endure seasonal effects & 2 \\
\hline Flexibility/adaptability of techniques & 3 \\
\hline Frequently maintenance & 4 \\
\hline Reliability/security & 1 \\
\hline
\end{tabular}

Social-cultural indicators

Awareness

\begin{tabular}{l} 
Participation in tenders \\
\hline Conpetice/nformat \\
\hline
\end{tabular}

Competence/information requirements

Web activity

Quality requirements

Work Safety Manuals

Labor accidents

\begin{tabular}{|l}
\hline Labor average age \\
\hline Work Safety
\end{tabular}

Work Safety Risk Assessment

Reclamations

Total risk is minimal
The methodologies for sustainability assessment will be used to determinate and elaborate the safety factors and parameters for mining advanced technology efficiency and for defining environmental impacts resulting from different mining processes. The sustainability assessment methods can be used for different purposes and at different levels: as a basis for decision-making when selecting among different remedial actions for a mined out area with time and financial constraints; to relate ground surface subsidence risk levels to acceptable risk levels established by the society for other activities. Particular attention will be paid to issues of current waste production and storage, old mining waste landfills, waste handling procedures, development of the framework for waste management. [5]

\section{CONCLUSION}

The limestone and dolostone are most expressive examples of the analysis, which show that it can be applied to other carbonate rock mining. Two different parameter scales have been used to compare limestone and dolostone to find out which one is more convenient. The elaborated sustainability assessment methods have shown that a three-level risk matrix monitoring scale gives more structured analyze results and it is recommended to use British Standard BS 8800 for the aspects gradation. The sustainability assessment methods can be used for different purposes and at different levels, such as a basis for decision-making when selecting among different remedial actions for a mined out area with time and financial constraints.

For successful development of a company in the long-term, the detailed recognition of external and internal factors affecting the company's development is required: dynamics of demand of consumers, formations of corporate culture and negotiation of weak aspects by optimal and effective use of internal resources, in particular. [3]

To carry through the final study of sustainable assessment Module Analyze determinations and measurements of impacts should be made for all Estonian carbonate deposits for developing an overall assessment of the sustainability measurement scale. The next step in this research is the sustainable analysis of Estonian oil shale. The real limitation of both the analyses conducted is the considerable amount of time which is needed for the analyses process. To make the analysis easier and to save time in the future, a Module Analyzing computer program should be prepared with the three-level risk matrix scale, which will make it possible to analyze the data more quickly. The research shows that the three - level risk matrix scale provides more accurate data analysis and it could be used for all aggregates. The final step of this research and the main aim to continue will be the estimation and rating of a company's sustainability status and recommendations for improvements, if necessary.

In the event that monthly reports are used for the analysis, then it is recommended to make analyze at least once every three months, but in this case the results have a dependency on the seasons. To avoid such inaccuracy, alternatively one can 
use bi-annual summary data reports, which allow carrying out the analysis infrequently and facilitates the application of the module analysis.

\section{ACKNOWLEDGEMENT}

Hereby special gratitude is expressed to the Estonian company OÜ Väo Paas for providing all necessary data and great teamwork. It was grateful to observe the work the mining company conducts, and the impression left after this cooperation, is of a successful company with a good team of employees.

The research was also supported by the Estonian Science Foundation (Grant "Backfilling and waste management in Estonian oil shale industry" No ETF8123 and Grant "Conditions of sustainable mining" No ETF7499) and by the project DAR8130 "Doctoral School of Energy and Geotechnology II" interdisciplinary research topic "Sustainable mining".

\section{REFERENCES}

1. Sabanov, S., Pastarus, J.-R., Shommet, J. Sustainability Assessment Methods in Oil Shale Mine Closure. In: 8-th International Scientific and Practical Conference, Rezekne, Latvia, June 20-22, 2011. Proceedings. Rezekne, 2011, p. 271-275.

2. Becker, B. Sustainability Assessment: A Review of Values, Concepts, and Methodological Approaches. Consultative Group on International Agricultural Research, 1997. 1 p.

3. Šommet, J., Pastarus, J.-R. Sustainable assessment in dolostone mining management. In: 11th International Symposium "Topical Problems in the Field of Electrical and Power Engineering", Doctoral Scholl of Energy and Geotechnology, Pärnu, Estonia, 16-21.01.2012 Proceedings Tallinn: Elektriajam, p. 244 - 246.

4. Laurence, D. Optimisation of the mine closure process. Journal of Cleaner Production, Volume 14, Issues 3-4, 2006. p. 285-298

5. Sabanov, S., Šommet, J., Milaševski, I., Bashkite, V., Gulevitš, J. Beldjaev, V., Robam, K. Sustainability assessment methods for developing advanced mining technologies. In: 9th International Symposium Pärnu 2010 "Topical Problems in the Field of Electrical and Power Engineering" and "Doctoral School of Energy and Geotechnology II”, Pärnu, Estonia, June 14 - 19, 2010: Tallinn University of Technology, 2010. pp. $69-74$.

6. EMAS Easy Version 1, EMAS for Small and Medium-Sized Business, 2012. pp. 2
7. BB 8800 Occupational Health and Safety Management Systems. BSI, June 2004

8. Koh, R., "The 80/20 Principle". Popurry, 2004. http://management.about.com/cs/generalmanagement/a/Pareto081202.ht m, 03/08/2012

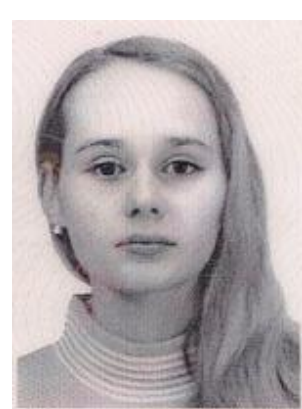

Julia Shommet earned at Tallinn University of Technology Mining Department a B.Sc. Geotechnology at 2006, also M.Sc. Geotechnology degree in 2009 and now is taking third year of $\mathrm{PhD}$ study. Supervisor is JüriRivaldo Pastarus and co-supervisor is Sergei Sabanov.

Is working for the OÜ Väo Paas company as the Quality Manager, Laboratory Technician at the testing laboratory and as a Safety Risk Expert as well as compiling all necessary documentation. Has substantial experience in all areas of macadam testing, risk safety manuals composing and safety risk assessment scheduling for Estonian Standards and requirements. Experience on this activity's is almost six years. Participating in teaching last two and a half years at Tallinn University of Technology Mining Department with the courses for bachelor students in Estonian language: Rock Mechanics, Rock Breaking and Processing, Marine Geotechnics and Elements of Engineering Geology.

E-mail: ohutu.tk@gmail.com

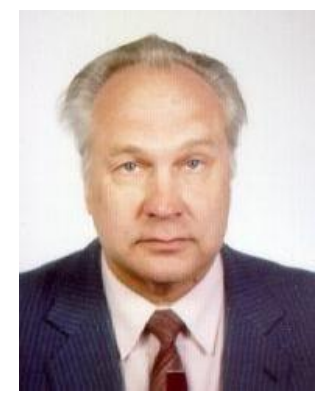

Juri - Rivaldo Pastarus has earned a Doctor's Degree in 1996 with the research "Large cavern stability in the Maardu granite deposit" at Tallinn University of Technology. Since 1985 and till present is Associate Professor of Tallinn University of Technology, Faculty of Power Engineering, Department of Mining, Chair of Mining Engineering. $\mathrm{He}$ is a member of Estonian Mining Society (EMS) and Head of Rock Mechanics Section; also member of World Business University Association (WBUA); Member of International Organizing Committee of International Conference "Environment. Technology. Resources."; Member of International Organizing Committee of International Symposium "Mine Planning and Equipment Selection" (MPES); Member of International Organizing Committee of International Symposium "Environmental Issues and Waste Management in Energy and Mineral Production" (SWEMP); since 2007 till present he is a Member of Educational Committee of Society of Mining Professors (SOMP); and also in other organizations.

E-mail: pastarus@cc.ttu.ee 